\title{
MODELING NUTRIENT BEHAVIOR IN WETLANDS
}

\author{
ROBERT H. KADLEC
}

Department of Chemical Engineering, The University of Michigan, Ann Arbor, MI $48109-2136$ (U.S.A.)

and DAVID E. HAMMER

Michigan Science and Engineering Associates, Ann Arbor, MI $48107-7105$ (U.S.A.)

(Accepted 16 December 1986)

\begin{abstract}
Kadlec, R.H. and Hammer, D.E., 1988. Modeling nutrient behavior in wetlands. Ecol. Modelling, 40: 37-66.

A simple mathematical model is developed which permits dynamic simulation of wetland hydrology and of nutrient-driven interactions between wastewater and the wetland ecosystem. Spatial variations due to surface water flow are described, and material balance calculations carried out for phosphorus, nitrogen, and chloride. A hydrology model, described elsewhere, predicts overland flow. Ecosystem phenomena are represented, using a one-dimensional, spatially distributed compartmental model. Compartments representing active parts of the ecosystem include soil, surface water, interstitial soil water, and various types of live biomass, standing dead and litter. Solutions to the partial differential equations which comprise these spatial models are demonstrated using finite-difference methods. Computer simulations are compared with operating data from the Porter Ranch wastewater treatment facility at Houghton Lake, Michigan. They accurately predict solute concentrations in surface water, biomass growth patterns, changes in the litter pool, and soil accretion rates.
\end{abstract}

\section{INTRODUCTION}

Advanced wastewater treatment is now required in many cases to upgrade - or at least maintain - the quality of our lakes and rivers. This consists of removal of dissolved components to very low levels, with phosphorus and nitrogen of special concern. Advanced treatment can involve a wide range of physico-chemical processing equipment, but these carry high capital and operating costs which are especially difficult for the small community to bear. Furthermore, the performance records of these advanced treatment systems are often extremely disappointing. As a result, 
increasing attention is being devoted to alternative treatment schemes, including wetland irrigation.

The simplicity and apparent success of wetland treatment systems have been demonstrated at a number of sites. In addition to natural wetlands, constructed wetlands have been employed. Wastewater quality at these sites has been improved before its release to lakes and streams. These were pioneering efforts, with planning based upon educated guesses about surface water hydrology and the ecosystem response to wastewater irrigation. Data is available from at least 26 sites (Hammer and Kadlec, 1983).

Since the knowledge base and the demand for such systems continue to expand, the need has emerged for reliable design procedures. The capability for predicting the performance of such treatment systems is obviously required before such facilities can receive broad acceptance by regulatory agencies, engineers, municipalities, and the ecological-science community. A wide range of performance questions arise with each new site proposed.

Mathematical models must be developed to predict the performance of wetland treatment systems. Since the majority of quantitative information available on natural wetland processes consists of autecological studies and studies of individual processes (e.g. litter decay), a compartmental material balance approach is indicated. This sort of model considers compartments such as surface water, plants, and soil, and accounts for changes within each by computing the material transfer rates between each pair. With all spatial transfers of material within the wetland tied to surface water movements, careful modeling of hydrology is prerequisite to all other calculations.

The object of the work which follows, is to develop tractable mathematical models to simulate the major interactions between wastewater and wetland ecosystems. To be useful in design, they must accommodate site specific information which invariably will be sparse in spatial distribution. The models will involve rate expressions in combination with compartment material balance, rates which may be impossible to obtain by direct measurement. As a result, certain rate constants must be fitted to theoretical or empirically plausible models to allow proper predictions of compartment contents. Partial differential equations (P.D.E.'s) reflecting changes with location and time make approximate numerical solutions unavoidable.

\section{BACKGROUND}

\section{Performance data}

A recent annotated bibliography of wetland research pertaining to wetland/wastewater interactions has been assembled by the U.S. Environmental Protection Agency (1984). From an engineering standpoint, much of the 
information on wetland/wastewater treatment systems is of marginal utility. This problem is due to three types of data limitations:

(1) Wetland systems are often treated as 'black-boxes' with only terminal streams quantified. Few investigators have used transects or 'distance-fromirrigation point' sampling.

(2) Complete material balance information is often missing. Usually this is due to difficulties in quantifying water flows. Concentrations reported without the associated flow rates make nutrient budget calculations impossible. Concentration data provides partial information on the spatial distribution of dissolved components, but is insufficient to determine rate parameters. Further, lack of hydrological data imposes uncertainty as to the actual effective/affected wetland area.

(3) Many investigations have begun after years of unmonitored wastewater discharge, and results consist of assay data on a single date. These 'point-in-time' studies provide quantitative information for various wetland compartments (e.g., soils, water, plants), but provide few clues as to seasonal variations or the history responsible for the present state. No rate information can be inferred, and equilibrium relationships remain rather speculative.

An extensive data base exists for the Porter Ranch site (Houghton Lake, MI). Spatial distribution of phosphorus, nitrogen and chloride in surface waters has been monitored each year, since fullscale wastewater discharge began in 1978 (Kadlec and Hammer, 1984). Background studies and pilot discharge experiments were performed during the period of 1972 through 1978. Hydrology at this site has been studied and generalized flow laws have been determined (Kadlec et al., 1981). While shallow depths, channelization and uncertain boundaries make it impractical to measure water flows directly within the wetland, combining hydrology predictions with site data permits material balances to be computed. Data on the spatial distribution of biomass in the vicinity of the wastewater irrigation zone and in unaffected areas have also been recorded for the Porter Ranch site.

\section{Previous wetland models}

The dynamics of wetlands have been represented by a variety of ecological models which describe or predict certain features, such as nutrient cycling or biomass productivity. Material balance calculations are most easily done using a compartmental model such as the one shown in Fig. 1. This type of model can be used to describe the quantities and material transfers associated with physical wetland entities. While many investigators have developed detailed compartmental models, often with great complexity, very few spatially distributed models have emerged (Mitsch, 1983). The mobility of waterborne components has been neglected in most wetland 


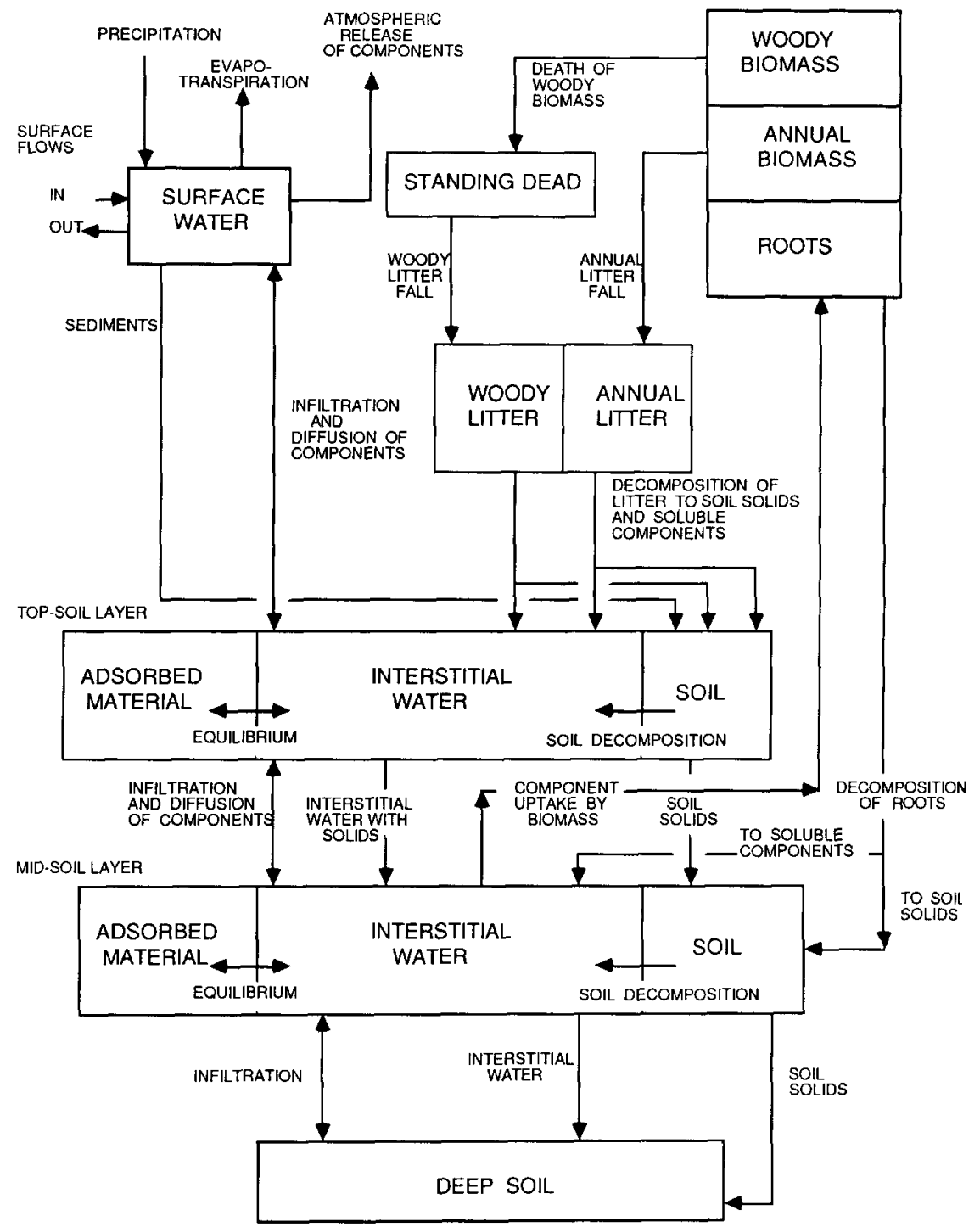

Fig. 1. Wetland ecosystem model

models. Appropriate water flow models should be incorporated into the overall analysis. From the mathematical standpoint, this has the effect of converting the wetland model from a set of ordinary differential equations to one which also contains partial differential equations. To avoid extensive calculations, stationary compartments models must be simple.

Hydrological models of wetlands have been reviewed by Mitsch et al. (1982). They describe three basic types: 'ecosystem' models and 'regional' 
models which account for the water budget, but do not address water movement, and 'hydrodynamic transport' models which describe stream flow and storm runoff. None of these approaches provide an adequate description of the thin sheet hydrology observed in many wetlands. Hammer and Kadlec (1986) have presented a model which was shown to represent the observed depths and flow rates at the Porter Ranch wetland/wastewater treatment site.

Models which are applicable to wastewater/ecosystem interactions include the spatial wetland model of Parker (1974). The computer simulation routine, REBUS (Routine for Executing Biological Unit Simulations), combines a compartmental representation of the ecosystem, with a topological structure which divides the wetland into blocks. Each block is assumed to be homogeneous throughout (e.g., uniform water level, solute concentrations, biomass, etc.) and connected to other blocks by flow streams. For surface water, the flow rate of each stream is computed using a simple rule, based upon the relative water levels of adjacent blocks. Detailed and quite complex models for vascular plants, standing dead material, litter, and soil have been developed for use with the REBUS similator (Dixon, 1974). This was the first spatially distributed model of a wetland ecosystem used to predict the impacts of wastewater irrigation. Results were consistent with the data and prevailing concepts at that time.

Six years of experience with wastewater irrigation at the Porter Ranch site identified a number of limitations in REBUS predictions:

(1) Hydrological predictions were poor. Data had not been available to test the model adequately. As the understanding of hydrology improved, the block structure of the REBUS routines prevented convenient implementation of more sophisticated mathematical models, requiring a relatively fine grid spacing for numerical solution.

(2) The compartmental models did not predict the observed changes in the above-ground live biomass and litter, despite the considerable complexity of the submodels.

(3) Certain wetland compartments were not incorporated into the REBUS model, such as interstitial soil water, which is now considered to be of substantial importance.

\section{MODEL DEVELOPMENT}

For engineering purposes, the best mathematical model should be the simplest which will adequately predict the changes and features of interest. It should include only those processes which are of primary importance. Submodels of individual processes should be simplified as much as possible. Spatial distribution of nutrients and other dissolved components due to 
water movements must be considered. Provisions in the submodels should allow for seasonal variations of rate contants, irregular irrigation schedules, winter freezing of the water sheet, rain events and other features of potential importance.

The removal of dissolved nutrients from surface waters is a two step process - consisting of delivery and consumption. Delivery is accomplished by convective mass transfer within surface waters, by sedimentation, or by downward infiltration flow. Consumption occurs principally at the surfaces of the soil, litter, plant stems and the algal mat. Four principal processes - biomass expansion, adsorption on peat, soil building, and microbial activity - collectively provide the consumption mechanisms. Adsorption will reach an equilibrium in the upper soil horizons, reducing the uptake rate. When the entire annual cycle is considered, the additional growth of biomass due to fertilization will consume nutrients only while the amount of biomass per unit area is increasing. This transient process, biomass expansion, will reach a saturation condition when the release of nutrients due to biomass offsets any uptake is new growth. Woody biomass production allows longer immobilization of nutrients and constitutes a relatively permanent removal mechanism. Soil production represents a long-term removal process, but is quite slow.

In the vicinity of the wastewater discharge a 'saturated' region will exist. Here component removal rates will be slow, comprised of the uptake due to (1) adsorption deep in the soil column, (2) incorporation of material into new soil and woody plants, and (3) microbial release of gases to the atmosphere.

Outside this 'saturated' region, surface water concentrations of wastewater components drop rapidly with distance. In the zone of rapid removal, it is the transport of dissolved components through the water sheet which limits the overall removal rate. The amount of wetland area needed for this zone will be determined by mass transfer considerations, and for constant operating conditions (i.e., depth, velocity, etc.) will not change.

Expansion of the affected region continues until the area is sufficient to allow all incoming wastewater components to be removed by infiltration flows, incorporation into new soil or woody biomass, or release to the atmosphere. If the available area is less than that required for total retention of pollutants, only a portion of the wastewater components fed to the wetland will be retained and the collection efficiency will drop sharply. This is called 'breakthrough'.

\section{Hydrological model}

A one-dimensional representation of the wetland surface has been selected for simplicity. A two-dimensional model, presenting a tremendously larger 
calculational task, is unwarranted for a number of reasons:

(1) For many natural wetlands, such as the Porter Ranch site, water flow is one-dimensional, since the wetland is roughly rectangular. The wetland simulation axis is chosen to correspond to the direction of maximum ground surface gradient, which is roughly parallel to the sides.

(2) As new facilities are designed, it is anticipated that constructed welands will dominate over natural sites. Such man-made systems will stress simple geometries for good water distribution and hydrological control, for example ditches or long, narrow cells.

(3) It is unlikely that sufficient data would be available at any site to validate a two-dimensional model. The availability of ground elevation data at even the most well-studied sites are insufficient to justify the extra dimension.

The description of this one-dimensional flow 'reactor' requires calculations of water movement, component concentrations in the water sheet, and amounts of materials in the non-moving biomass and soil. The water flow computations are independent of other processes, except in the very long term. Good calculation procedures are available and have been described elsewhere (Kadlec et al., 1981; Hammer and Kadlec, 1986). The depths and velocities are thus known function of position and time.

Typical water depths in a wetland may range from a few centimeters to about $1 \mathrm{~m}$. Spatial variations are largely due to changes in the elevation of the underlying soil. The water sheet is relatively flat with very small surface gradients. Wastewater, introduced to the wetland, will spread from the discharge points, and if the irrigation rate is sufficiently high, a shallow mound of water (not exceeding $10 \mathrm{~cm}$ ) will form. This mound will not exceed about $10 \mathrm{~cm}$, but the height will be determined by the discharge rate and wetland properties.

The water will move away from the discharge through the wetland vegetation, which presents obstructions to flow. This vegetative mat comprises a doubly porous medium, with plant stems, and litter forming fine-scale porosity, while hummocks, islands and channels cause a coarsescale porosity. There can be a difference between the porosity for water storage and the pore space available for water flow. Water may soak into hummocks, for example, but they still provide an obstacle to overland flow. The apparent porosities can be expected to vary with water depth.

Flow patterns, even though one dimensional, are not simple. Flow reversals can occur in a system with changing inputs. As many as four changes in flow direction across the water sheet, have been demonstrated for the Porter Ranch site. Rain events cause sudden and dramatic changes in rates and directions. 


\section{Ecosystem model}

The simulation model of the weland ecosystem consists of compartments shown in Fig. 1. Solid arrows represent the transfer of solids between compartments, while the dashed arrows represent exchange of dissolved components, such as nitrogen, phosphorus and chloride. Dynamic material balance calculations account for changes in the concentration of dissolved components in surface water, in interstitial soil waters, for changes in the amounts of various types of biomass and for changes in the soil solids present.

This model is formulated to use wetland site information, recognizing the limitations of available and potential data for specific ecosystems. There remain a number of parameters not easily obtained for a new site, but as knowledge increases generalizations should mitigate this problem.

This ecosystem model includes nine solids compartments and three water compartments. These compartments are spatially distributed with variations in the mount and composition of material present due to nutrient transport by moving surface waters. The solids compartments are:

(1) Annual biomass - This consists of all live, above-ground vascular plant tissues which undergo an annual growth/death cycle. This includes sedges, grasses, other miscellaneous non-woody plants and leaves of deciduous woody plants.

(2) Woody biomass - This consists of all live, above-ground woody plant tissues which persist for many years. This compartment includes the woody portion of plants such as bog-birch, willow, leatherleaf and aspen.

(3) Standing dead - This consists of dead above-ground biomass which has not fallen to wetland surface. This compartment consists of woody plant tissues, but could also include dead sedges, cattails, and other annual material.

(4) Roots - This compartment is made up by the total live and dead underground biomass.

(5) Annual litter - This consists of the dead, decaying biomass which came from the annual biomass compartment.

(6) Woody litter - This consists of the dead and decaying biomass which came from the standing dead compartment.

(7) Top-soil layer - This is a vertically moving, constant volume compartment, beginning at the wetland surface, and extending downward a specified distance. If solids are deposited, this compartment moves upward in the soil column. This soil layer physically encloses a corresponding interstitial water compartment.

(8) Mid-soil layer - This compartment is entirely analogous to the topsoil layer, moving vertically as material accumulates. It is located immediately below the top-soil layer. 


\section{NOMENCLATURE}

List of symbols used

\begin{tabular}{|c|c|c|}
\hline Variable & Definition & Units \\
\hline $\bar{a}$ & Adsorption coefficient, defined in Table 1 & \\
\hline$A$ & Water addition rate & $\mathrm{m} \mathrm{day}^{-1}$ \\
\hline$b$ & Adsorption exponent, define in Table 1 & \\
\hline$B$ & Live biomass & $\mathrm{kg} \mathrm{m}^{-2}$ \\
\hline C & Solute concentration in water & $\mathrm{kg} \mathrm{m}^{-3}$ \\
\hline$d$ & Surface water depth & $\mathrm{m}$ \\
\hline$D_{\mathrm{A}}$ & Fall rate of annual biomass & day $^{-1}$ \\
\hline$D_{\mathrm{LA}}$ & Decay rate of annual litter (winter) & day $^{-1}$ \\
\hline$D_{\mathrm{LW}}$ & Decay rate of woody litter (winter) & day $^{-1}$ \\
\hline$D_{\mathrm{M}}$ & Fall rate of standing dead & day $^{-1}$ \\
\hline$D_{\mathrm{MS}}$ & Decomposition rate of mid-soil (winter) & day $^{-1}$ \\
\hline$D_{\mathrm{R}}$ & Decay rate of roots (winter) & day $^{-1}$ \\
\hline$D_{\mathrm{TS}}$ & Decompositon rate of top-soil (winter) & day $^{-1}$ \\
\hline$D_{\mathrm{W}}$ & Death rate of woody biomass & day $^{-1}$ \\
\hline$E$ & Evapotranspiration rate & $m$ day $^{-1}$ \\
\hline$F$ & Net flux of nutrients to the root zone & $\mathrm{kg} \mathrm{m}^{-2} \mathrm{day}^{-1}$ \\
\hline$F_{\mathrm{LS}}$ & Fraction of decaying litter which becomes soil solids & \\
\hline$F_{\mathrm{RS}}$ & Fraction of decaying roots which becomes soil solids & \\
\hline$G$ & Total uptake of limiting nutrient by vascular plants & $\mathrm{kg} \mathrm{m}^{-2}$ day $^{-1}$ \\
\hline$K_{\mathrm{SC}}$ & Mass transfer coefficient in the soil column & m day ${ }^{-1}$ \\
\hline$K_{\mathrm{w}}$ & Mass transfer coefficient through the surface water & $m$ day $^{-1}$ \\
\hline$L$ & Litter biomass & $\mathrm{kg} \mathrm{m}^{-2}$ day $^{-1}$ \\
\hline$M$ & Standing dead biomass & $\mathrm{kg} \mathrm{m}^{-2} \mathrm{day}^{-1}$ \\
\hline$P$ & Precipitation & $m$ day $^{-1}$ \\
\hline$R_{\mathrm{ATM}}$ & Component release rate to the atmosphere & $\mathrm{kg} \mathrm{m}^{-3} \mathrm{day}^{-1}$ \\
\hline$R_{\text {INF }}$ & Water infiltration rate & $\mathrm{m}_{\text {day }}{ }^{-1}$ \\
\hline$R_{\mathrm{S} 1}$ & Transfer rate of soil solids from top- to mid-soil layer & $\mathrm{kg} \mathrm{m}^{-2} \mathrm{day}^{-1}$ \\
\hline$R_{\mathrm{S} 2}$ & Net accumulation rate of soil solids & $\mathrm{kg} \mathrm{m}^{-2} \mathrm{day}^{-1}$ \\
\hline$R_{\mathrm{SED}}$ & Sediment production rate & $\mathrm{kg} \mathrm{m}^{-2} \mathrm{day}^{-1}$ \\
\hline$R_{\mathrm{W}}$ & Net component flux to surface water sheet & $\mathrm{kg} \mathrm{m}^{-2}$ day $^{-1}$ \\
\hline$S_{\mathrm{M}}$ & Dry solids in mid-soil layer & $\mathrm{kg} \mathrm{m}^{-2}$ \\
\hline$S_{\mathrm{T}}$ & Dry solids in top-soil layer & $\mathrm{kg} \mathrm{m}^{-2}$ \\
\hline$t$ & Time & day \\
\hline$v$ & Superficial velocity of surface water & $\mathrm{m} \mathrm{day}^{-1}$ \\
\hline$x$ & Mass fraction of component in solids compartment & $\mathrm{kg} \mathrm{kg}^{-1}$ \\
\hline$x$ & Location along spatial axis & $\mathrm{m}$ \\
\hline$\gamma$ & Ratio of summer decay rates to winter decay rates & \\
\hline$\pi_{1}$ & Volume of interstitial soil water per unit mass of dry soil & $\mathrm{m}^{3} \mathrm{~kg}^{-1}$ \\
\hline$\pi_{2}$ & Volume of interstitial water in top-soil layer per unit area & $\mathrm{m}^{3} \mathrm{~m}^{-2}$ \\
\hline$\pi_{3}$ & Volume of interstitial water in mid-soil layer per unit area & $\mathrm{m}^{3} \mathrm{~m}^{-2}$ \\
\hline$\pi_{4}$ & $\begin{array}{l}\text { Root zone capacity parameter from plant sub-model, defined } \\
\text { Fig. } 16\end{array}$ & $\mathrm{~m} \mathrm{day}^{-1}$ \\
\hline$\Phi$ & Porosity, fraction of volume available for water & \\
\hline
\end{tabular}


NOMENCLATURE (continued)

\begin{tabular}{ll}
\hline Variable & Definition \\
\hline \multicolumn{2}{l}{ global subscripts } \\
a & Denotes added water \\
A & Denotes annual biomass \\
D & Denotes deep soil \\
g & Denotes ground or subsurface \\
M & Denotes mid-soil water solute concentration \\
MAX & Denotes maximum growth rate \\
MS & Denotes mid-soil layer \\
P & Denotes precipitation \\
PEAK & Denotes maximum biomass \\
R & Denotes root compartment \\
S & Denotes surface water \\
SMIN & Denotes minimum useable nutrient concentration in the root \\
& zone, as defined in the plant sub-model \\
T & Denotes top-soil water solute concentration \\
TS & Denotes the top-soil layer \\
W & Denotes woody biomass \\
\hline
\end{tabular}

(9) Deep soil - This compartment is the ultimate sink for accumulated solids. It is generally an expanding pool, and also contains the interstitial solutes.

Surface water component balances are described by the following equations:

$\frac{\partial C}{\partial t}=\frac{v}{\Phi_{\mathrm{S}}} \frac{\partial C}{\partial z}+R_{\mathrm{w}} \frac{1}{\Phi_{\mathrm{S}} d}$

where

$$
\begin{aligned}
R_{\mathrm{W}}= & \left(C_{\mathrm{P}}-C\right) P+\left(C_{\mathrm{a}}-C\right) A+C E-K_{\mathrm{W}}\left(C-C_{\mathrm{T}}\right) \\
& -R_{\mathrm{SED}} x_{\mathrm{SED}}- \begin{cases}\left(C_{\mathrm{T}}-C\right) R_{\mathrm{INF}} & \text { if } R_{\mathrm{INF}}<0.0 \\
0 & \text { if } R_{\mathrm{INF}} \geqslant 0.0\end{cases}
\end{aligned}
$$

The rate and composition of sediments $\left(R_{\mathrm{SED}}, x_{\mathrm{SED}}\right)$ can be computed from a sediment model if desired. Correlations for the mass transfer coefficient for wetland flows, $K_{\mathrm{w}}$, have been presented elsewhere (Kadlec and Hammer, 1982). The porosity $\Phi_{\mathrm{s}}$ is a function of shoot density, clump patterns and channelization; it must be estimated for the specific site and cover-type. Adjustment of the coefficient, $K_{\mathrm{w}}$, and the estimated porosity, $\Phi_{\mathrm{S}}$, are discussed in a later section. This was needed to better reflect the clump/ channel structure and to correct discrepancies observed in the simulation results for the Porter Ranch site. Average annual values for these hydrological parameters were sufficient to describe water flows throughout the year. 
Insufficient data were available at this site to include year-to-year changes of the above-ground biomass into prediction of porosity and hydraulic conductivity. All other quantities are available as site-specific data $\left(C_{\mathrm{P}}, C_{\mathrm{A}}, P, E\right.$, $R_{\mathrm{INF}}$ ), or are computed using the hydrology model $(v, d)$.

Balance equations for the solids compartments are:

$$
\begin{aligned}
& \frac{\partial B_{\mathrm{W}}}{\partial t}=G_{\mathrm{W}}-D_{\mathrm{W}}\left(B_{\mathrm{W}}\right)_{\mathrm{PEAK}} \\
& \frac{\partial B_{\mathrm{A}}}{\partial t}=G_{\mathrm{A}}-D_{\mathrm{A}}\left(B_{\mathrm{A}}\right)_{\mathrm{PEAK}} \\
& \frac{\partial B_{\mathrm{R}}}{\partial t}=G_{\mathrm{R}}-D_{\mathrm{R}}\left(B_{\mathrm{R}}\right)_{\mathrm{PEAK}} \\
& \frac{\partial L_{\mathrm{A}}}{\partial t}=D_{\mathrm{A}}\left(B_{\mathrm{A}}\right)_{\mathrm{PEAK}}-D_{\mathrm{LA}}\left(L_{\mathrm{A}}\right)_{\mathrm{PEAK}} \\
& \frac{\partial L_{\mathrm{W}}}{\partial t}=D_{\mathrm{M}} M_{\mathrm{PEAK}}-D_{\mathrm{LW}}\left(L_{\mathrm{W}}\right)_{\mathrm{PEAK}} \\
& \frac{\partial M}{\partial t}=D_{\mathrm{W}}\left(B_{\mathrm{W}}\right)_{\mathrm{PEAK}}-D_{\mathrm{M}} M_{\mathrm{PEAK}} \\
& \frac{\partial S_{\mathrm{D}}}{\partial t}=R_{\mathrm{S} 2} \\
& R_{\mathrm{S} 2}=R_{\mathrm{S} 1}+F_{\mathrm{RS}} D_{\mathrm{R}}\left(B_{\mathrm{R}}\right)_{\mathrm{PEAK}}-D_{\mathrm{MS}} S_{\mathrm{M}} \\
& R_{\mathrm{S} 1}=R_{\mathrm{SED}}-D_{\mathrm{TS}} S_{\mathrm{T}}+F_{\mathrm{LS}} D_{\mathrm{LA}}\left(L_{\mathrm{A}}\right)_{\mathrm{PEAK}}+F_{\mathrm{LS}} D_{\mathrm{LW}}\left(L_{\mathrm{W}}\right)_{\mathrm{PEAK}}
\end{aligned}
$$

The depletion of each biomass pool is expressed as the product of a constant rate factor (e.g., $\left.D_{\mathrm{W}}\right)$ and the peak pool biomass (e.g., $\left.\left(B_{\mathrm{W}}\right)_{\text {PEAK }}\right)$. With the exception of deep soil, composition of these solids are considered to be constant, thus component balances are simple multiples of these equations. In recognition of seasonal effects, summer decay rates are presumed to be a specified multiple, $\gamma$, of the winter rates and estimated from field data; the growing season duration is specified, as is the period for autumn leaf fall. Translocation is not explicitly contained in this model. The annual biomass pool begins empty in early spring and produces the peak crop by the last day of the growing season. While different species may reach their standing crop peak at somewhat different times, this simplification proved successful in describing the biomass pool as measured in the field. This peak crop is converted to annual litter before winter. Data showed that the amount standing dead from the annual biomass compartment is negligible at the Porter Ranch site. The death rate for woody biomass $\left(D_{\mathrm{w}}\right)$, and proportions relating underground biomass to above-ground live biomass are estimated from field data. Therefore with knowledge of the peak biomass pool sizes at 
a given site, computation of growth rates, decay rates and biomass fall/death rates $\left(G_{\mathrm{A}}, G_{\mathrm{W}}, G_{\mathrm{R}}, D_{\mathrm{A}}, D_{\mathrm{R}}, D_{\mathrm{LA}}, D_{\mathrm{LW}}\right.$, and $\left.D_{\mathrm{m}}\right)$ can be completed using equations. 3-11. Further, with specification of soil compartment sizes ( $S_{\mathrm{T}}$, $\left.S_{\mathrm{M}}\right)$, the net soil accumulation rate $\left(R_{\mathrm{S} 2}\right)$, and the mass fractions of decaying litter and roots that become soil soils $\left(F_{\mathrm{LS}}\right.$ and $\left.F_{\mathrm{RS}}\right)$, the soil decomposition rates in the top and mid-soil compartments $\left(D_{\mathrm{TS}}, D_{\mathrm{MS}}\right)$ can be computed for the stationary-state case. If the soil decay rate is not considered uniform, one additional parameter must be set, the ratio of decomposition rates $\left(D_{\mathrm{TS}} / D_{\mathrm{MS}}\right)$. It should be noted that many of these parameters can be expected to be site specific.

Interstitial water compartments involve more complex transfers of nutrients and other soluble components. The top-soil interstitial water balance equation is:

$$
\begin{aligned}
\frac{\partial C_{\mathrm{T}}}{\partial t} & \\
= & \left(K_{\mathrm{W}}\left(C-C_{\mathrm{T}}\right)+x_{\mathrm{TS}} D_{\mathrm{TS}} S_{\mathrm{T}}-R_{\mathrm{ATM}} \pi_{1}+\left(x_{\mathrm{LA}}-F_{\mathrm{LS}} x_{\mathrm{TS}}\right) D_{\mathrm{LA}}\left(L_{\mathrm{A}}\right)_{\mathrm{PEAK}}\right. \\
& +\left(x_{\mathrm{LW}}-F_{\mathrm{LS}} x_{\mathrm{TS}}\right) D_{\mathrm{LW}}\left(L_{\mathrm{W}}\right)_{\mathrm{PEAK}}+\left\{\begin{array}{ll}
R_{\mathrm{INF}}\left(C-C_{\mathrm{T}}\right) & \text { for } R_{\mathrm{INF}} \geqslant 0 \\
R_{\mathrm{INF}}\left(C_{\mathrm{T}}-C_{\mathrm{M}}\right) & \text { for } R_{\mathrm{INF}}<0
\end{array}\right\} \\
& -\left\{\begin{array}{ll}
R_{\mathrm{S} 1}\left(a C_{\mathrm{T}}^{b-1}+\pi_{1}\right) C_{\mathrm{T}} & \text { for } R_{\mathrm{S} 1} \geqslant 0 \\
R_{\mathrm{S} 1}\left(a C_{\mathrm{M}}^{b-}+\pi_{1}\right) C_{\mathrm{M}} & \text { for } R_{\mathrm{S} 2}<0
\end{array}\right\} \\
& -K_{\mathrm{SC}}\left(C_{\mathrm{T}}-C_{\mathrm{M}}\right) /\left(\pi_{2}+a b C_{\mathrm{T}} S_{\mathrm{T}}\right)
\end{aligned}
$$

New parameters in the model with inclusion of this compartment include $R_{\mathrm{ATM}}, a, b$, and $K_{\mathrm{SC}}$. The rate of component release to the atmosphere, $R_{\mathrm{ATM}}$, can be estimated if desired, from a model of micro-organism activity. The adsorption equilibrium contants $a$ and $b$ are available from laboratory studies with peat soils (Kadlec and Hammer, 1981). Typical values are shown in Table 1 . The mass transfer coefficient within the soil column, $K_{\mathrm{SC}}$, can be estimated from measurements of nutrient diffusion through peat soils (Patrick and Reddy, 1976). There are not drastically different from the diffusivities observed in water, for peat soils contain $80 \%$ moisture or more. Due to the compartment structure chosen, with roots arbitrarily isolated in the midsoil layer, adjustment of $K_{\mathrm{SC}}$ is necessary, as discussed in the next chapter, to account for intrusion of some roots into the top-soil layer.

Since data are lacking for wastewater irrigation sites, litter decomposition is presumed to result in soil solids of a constant composition. This is taken to be the undisturbed soil composition specified from stationary-state data, $x_{\text {TS }}$. 


\section{TABLE 1}

Adsorption constants for sedge peat soils

\begin{tabular}{lll}
\hline Solute & $a$ & $b$ \\
\hline $\mathrm{N}$ in $\mathrm{NH}_{4}^{+1}$ & $2.71 \times 10^{-3}$ & 0.85 \\
$\mathrm{P}$ in $\mathrm{PO}_{4}^{-3}$ & $7.55 \times 10^{-3}$ & 0.46 \\
$\mathrm{Cl}$ in $\mathrm{Cl}^{-1}$ & 0.0 & 0.0 \\
\hline
\end{tabular}

Note: $\left[\mathrm{kg}\right.$ solute adsorbed $\mathrm{kg}^{-1} \mathrm{dry}$ soil $]=a\left[\mathrm{~kg} \text { solute } \mathrm{m}^{-3}\right]^{b}$.

The component balance for the mid-soil interstitial water is:

$$
\frac{\mathrm{d} C_{\mathrm{M}}}{\mathrm{d} t}=(F-G) /\left(\pi_{3}+a b C_{\mathrm{M}}^{b-1} S_{\mathrm{M}}\right)
$$

where

$$
\begin{aligned}
F= & K_{\mathrm{SC}}\left(C_{\mathrm{T}}-C_{\mathrm{M}}\right)+x_{\mathrm{MS}} D_{\mathrm{MS}} S_{\mathrm{M}}+\left\{\begin{array}{cc}
R_{\mathrm{INF}}\left(C_{\mathrm{T}}-C_{\mathrm{M}}\right) & \text { for } R_{\mathrm{INF}}>0 \\
0 & \text { for } R_{\mathrm{INF}} \leqslant 0
\end{array}\right\} \\
& + \begin{cases}R_{\mathrm{S} 1}\left(a C_{\mathrm{T}}^{b-1}+\pi_{1}\right) C_{\mathrm{T}} & \text { for } R_{\mathrm{S} 1} \geqslant 0 \\
R_{\mathrm{S} 1}\left(a C_{\mathrm{T}}^{b-1}+\pi_{1}\right) C_{\mathrm{M}} & \text { for } R_{\mathrm{S} 1}>0\end{cases}
\end{aligned}
$$

and

$$
G=x_{\mathrm{A}} G_{\mathrm{A}}+x_{\mathrm{w}} G_{\mathrm{W}}+x_{\mathrm{R}} G_{\mathrm{R}}
$$

Root decay is considered to produce soil solids of a constant composition, $x_{\mathrm{MS}}$, as discussed above for litter. The nutrient dynamics in the mid-soil layer involve and determine plant growth.

Biomass compositions $\left(x_{\mathrm{A}}, x_{\mathrm{W}}\right.$, and $\left.x_{\mathrm{R}}\right)$ are considered to be constant. The growth rates $G_{\mathrm{A}}, G_{\mathrm{W}}$, and $G_{\mathrm{R}}$ are determined by the nutrient supply; the limiting nutrient will thus determine these rates. A simple set of plant growth rules were adopted, representing an overall average for the species: plants will grow at the average maximum rate permitted by the nutrient supply in the midsoil interstitial water, subject to two constraints, growth rate cannot exceed a specified multiple of the unfertilized rate (e.g., $5 \times$ ); and nutrients can be utilized only down to a specified lower limit of concentration in the mid-soil layer, $C_{\mathrm{SMIN}}$. Since various nutrients are used in fixed ratios during biomass generation, the growth rate will be determined by the limiting nutrient, if any. Annual, woody, and root biomass pools will expand in the same relative proportions.

The final balance equations are those which account for changes in solids 
compositions in the top- and mid-soil compartments. These material balances are:

$$
\begin{aligned}
\frac{\mathrm{d} x_{\mathrm{TS}}}{\mathrm{d} t}= & \frac{R_{\mathrm{SED}}}{S_{\mathrm{T}}} x_{\mathrm{SED}}+x_{\mathrm{TS}} \frac{F_{\mathrm{LS}}}{S_{\mathrm{T}}}\left(D_{\mathrm{LA}}\left(L_{\mathrm{A}}\right)_{\mathrm{PEAK}}+D_{\mathrm{LW}}\left(L_{\mathrm{W}}\right)_{\mathrm{PEAK}}\right) \\
& -D_{\mathrm{TS}} x_{\mathrm{TS}}- \begin{cases}R_{\mathrm{S} 1} x_{\mathrm{TS}} / S_{\mathrm{T}} & \text { if } R_{\mathrm{S} 1} \geqslant 0 \\
R_{\mathrm{S} 1} x_{\mathrm{MS}} / S_{\mathrm{T}} & \text { if } R_{\mathrm{S} 1}<0\end{cases} \\
\frac{\mathrm{d} x_{\mathrm{MS}}}{\mathrm{d} t}= & x \frac{F_{\mathrm{RS}}}{S_{\mathrm{M}}} D_{\mathrm{R}}\left(B_{\mathrm{R}}\right)_{\mathrm{PEAK}}-\left\{\begin{array}{ll}
x_{\mathrm{S}} R_{\mathrm{S} 2} / S_{\mathrm{M}} & \text { if } R_{\mathrm{S} 2}<0 \\
x_{\mathrm{MS}} R_{\mathrm{S} 2} / S_{\mathrm{M}} & \text { if } R_{\mathrm{S} 2} \geqslant 0
\end{array}\right\} \\
& -D_{\mathrm{MS}} x_{\mathrm{MS}}+ \begin{cases}x_{\mathrm{TS}} R_{\mathrm{S} 1} / S_{\mathrm{M}} & \text { if } R_{\mathrm{S} 1} \geqslant 0 \\
x_{\mathrm{MS}} R_{\mathrm{S} 1} / S_{\mathrm{M}} & \text { if } R_{\mathrm{S} 1}<0\end{cases}
\end{aligned}
$$

\section{Boundary conditions}

Five alternatives were developed for specification of conditions at the upstream and downstream ends of the wetland. These include flow control and level control as well as a no-flow shore condition. Since outlet structures are likely in constructed wetlands, provision was made for weir and pooland-weir flow control. Inlet concentrations of nutrients must be specified.

\section{Initial conditions}

Large scale simulations of ecosystem response to external driving forces require a starting condition. Even the simplest simulation requires very large amounts of CPU time (money) to calculate for a short span of time (Parker, 1974). If initial conditions are chosen which are not consistent with a reasonable starting annual cycle, then several years of simulation are needed simply to recover from the bad starting guesses. To avoid this difficulty, it is possible to compute a final stationary state for a periodic disturbance, such as a repeated addition of nutrient-rich treated wastewater (Gupta, 1977). If the external driving forces are not periodic - and they rarely are - then the simulation must start at a viable repetitive starting state. This model provides such a capability.

\section{NUMERICAL SOLUTION}

The partial differential equations which describe surface water flow and the associated movement of dissolved components were solved by finite difference methods. Data were available to support model calculation of nitrogen, phosphorus and chloride distributions, as well as biomass. The ecosystem reactions to extra nutrients are quite slow compared to the time 
scale needed to describe surface water movement. Biomass expansion and other natural changes in the wetland ecosystem have negligible impact upon the direction and rate of water flow. Thus, the hydrology was solved first, using a short time step and a fine spatial grid. The resulting daily values of depth and velocity were retained for subsequent ecosystem calculations, with the option of using larger time and/or spatial steps. However, studies with the simulator showed that material transfers between stationary wetland compartments were more rapid than expected - the time scales for hydrology and for exchange between interstitial water compartments were found to be of the same order. Rain events and variations in the irrigation schedule affect nutrient concentrations on a day to day basis.

Solution attempts using backward finite differences for the spatial derivative proved inadequate. Concentration perturbations traveled at approximately the speed of integration (distance step/time step) rather than being constrained by surface water velocities. A dual spatial grid was established, as shown in Fig. 2. The coarse grid is employed for integration of all of the solids and interstitial water compartments. The fine grid is used only to describe variations in solute concentrations throughout the water sheet. For each fine grid interval, input and output streams (if any) were identified and the concentration change updated as if it were a well-mixed cell. Special treatment of cells with no inlets, no outlets or no surface water was necessary. Integration of the fine grid cell concentration was accomplished using one or two step methods with the derivative evaluation based upon the mean concentration encountered across the time step.

Mass transfer quantities $\left(\mathrm{kg} \mathrm{m}^{-2}\right)$ computed for each fine grid interval are then mapped back onto the appropriate coarse grid block of interstitial water. Large nutrient fluxes were found in interstitial water compartments, not only due to wastewater irrigation, but more importantly in response to biomass decomposition and uptake by growing plants. These rapid rates required shorter time steps for stable integration. As a result, surface water and interstitial water compartments were updated using a short time step, while the remaining stationary compartments (biomass and soil) were integrated with a simple Euler method, and solids compartments were handled

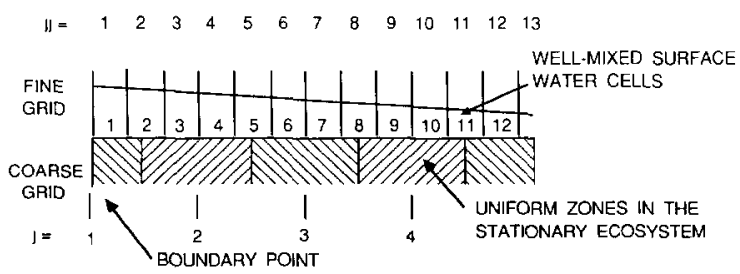

Fig. 2. Schematic diagram of the zone of affected soil and biomass due to wastewater irrigation. 


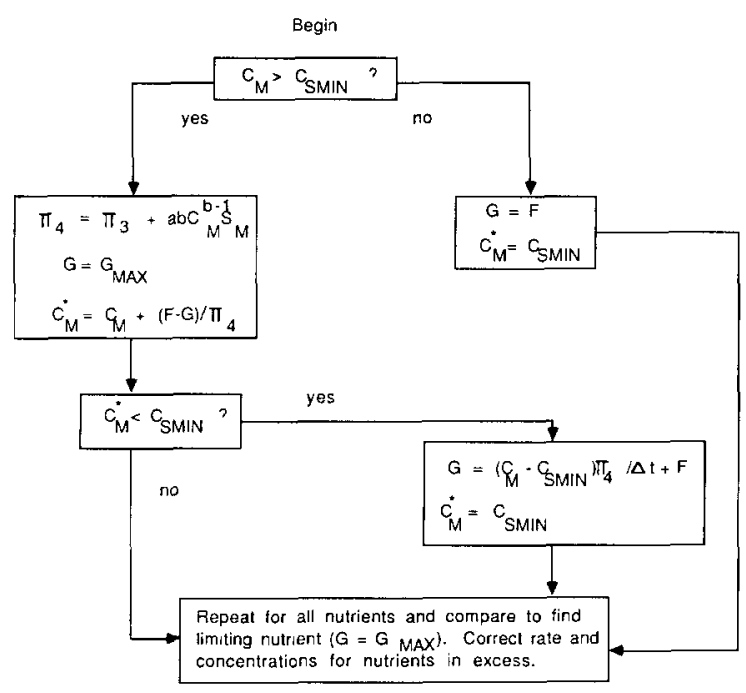

Fig. 3. Biomass nutrient uptake model reduced to a calculational algorithm. Notes: $F$ is the net nutrient flux into the root zone. $C_{\mathrm{M}}$ is the interstitial concentration in the mid-soil layer at the beginning of the time step, $\Delta t . C_{\mathrm{M}}$ is the updated concentration prediction at the end of the time step.

with a Runge-Kutta technique. During the winter, when surface water is immobile, the Runge-Kutta method was used for all compartments with a single step spanning the entire winter.

The biomass growth model was implemented in the numerical solution for nutrient budgets in the mid-soil compartment. The algorithm used is shown in Fig. 3.

The routines described above predict the changes in surface water concentrations and biomass observed at the Porter Ranch site. The numerical solutions are stable and insensitive to time step, so long as the ratio of the fine grid interval to time step is greater than about twice the maximum local water velocity. Numerical integration of surface water cells must update concentrations at a rate greater than the rate at which the cell volume is displaced by input flow. Longer time steps cause instabilities, first in chloride concentrations in cells which experience high velocities. This is due to the low chloride capacity of the top-soil interstitial water compartment. Additional capacity is available for nutrients due to adsorption phenomena, and this stabilizes the numerical solution for phosphorus and nitrogen with shorter time steps. In addition, if depth of surface water in any given cell falls below about $2 \mathrm{~cm}$, it is treated as an isolated region, with no flow in or out. Without this provision the low volume leads to numerical instabilities due to high velocities. Cell isolation amounts to a 'puddling' phenomena, 
which seems reasonable for very shallow water in an irregular terrain. A fine grid spacing of $10 \mathrm{~m}$ proved adequate to accurately predict concentration front movement in response to wastewater addition. The coarse grid was used to subdivide the stationary compartments and to provide locations at which the results of foregoing hydrological calculations are matched. A coarse grid interval of approximately $80 \mathrm{~m}$ was used with good results.

\section{SIMULATION RESULTS AND MODEL VERIFICATION}

Data from the Porter Ranch site spanning more than 6 years (Kadlec, 1979; Kadlec and Hammer, 1980) were used to test and fit the hydrological and ecosystem models. Water elevation stations were surveyed into place in 1979 and the measurements from those locations provided the most accurate data for use with the hydrological model. Wastewater irrigation began in late summer of 1978 . This provided a starting point from an undisturbed (repetitive) condition for the wetland ecosystem, and model calculations were begun with this first application of wastewater. The quantity of numerical information necessary to describe the ecosystem condition is substantial. The instantaneous status of the ecosystem compartments and water sheet, in terms of nutrients and biomass, requires seven pages of tables. The time history is therefore voluminous.

\section{Ecosystem response}

Site-specific data include initial solute concentrations, the peak biomass in each of the solids compartments, compositions for biomass and soils, adsorption constants, and solute concentrations in precipitation and in incoming streams. These values were supplied as data from field measurements. Certain parameter values were set based upon data interpretation and heuristic arguments, these are summarized in Table 2.

From these data and specifications, many rate parameters (e.g., decay rates) were computed for the stationary-state starting condition. These calculations also provided initial values for each biomass pool on any specified starting day. Table 3 shows the results obtained from such stationary-state calculations. The rates computed for litter decay, soil decomposition, etc. (at stationary-state) were then used in subsequent dynamic simulation.

Model parameters describing the transport of nutrients $\left(K_{\mathrm{W}}\right.$ and $\left.K_{\mathrm{SC}}\right)$ were fitted by trial and error. Values were adjusted to give the proper areal expansion rate for the affected biomass region surrounding the discharge. The mass transfer coefficient, $K_{\mathrm{SC}}$, (exchange between top- and mid-soil) was found to be unreasonably low for nutrients, but not for chloride, when predicted solely by soil column diffusion. As a result the value of $K_{\mathrm{SC}}$ was increased by a factor of 1000 for phosphorus and nitrogen. This large 
TABLE 2

Ecosystem model parameter assumptions

\begin{tabular}{|c|c|c|}
\hline Term & Definition & Value \\
\hline$F_{\mathrm{LS}}$ & $\begin{array}{l}\text { Fraction of decaying litter solids which become } \\
\text { soil solids }\end{array}$ & 0.20 \\
\hline$F_{\mathrm{RS}}$ & $\begin{array}{l}\text { Fraction of decaying root solids which become } \\
\text { soil solids }\end{array}$ & 0.25 \\
\hline$\gamma$ & $\begin{array}{l}\text { Ratio of summer decay rates to winter decay } \\
\text { rates }\end{array}$ & 10 \\
\hline$D_{\mathrm{w}}$ & Death rate of woody biomass & 0.000274 day $^{-1}$ \\
\hline$D_{\mathrm{TS}} / D_{\mathrm{MS}}$ & Ratio of top-soil decay rate to mid-soil decay rate & 10 \\
\hline$R_{\mathrm{S} 2}$ & Net soil accumulation rate & $-8 \times 10^{-6} \mathrm{~kg} \mathrm{~m}^{-2}$ \\
\hline$R_{\mathrm{SED}}$ & Sediment formation rate & 0.0 \\
\hline$R_{\mathrm{ATM}}$ & $\begin{array}{l}\text { Atmospheric release of nutrients by microbial } \\
\text { mechanisms }\end{array}$ & 0.0 \\
\hline$C_{\text {SMIN }}$ & $\begin{array}{l}\text { Minimum root-zone nutrient concentrations (for } \\
\text { use in the plant sub-model) }\end{array}$ & $\begin{array}{l}\mathrm{N}: 1 \times 10^{-5} \mathrm{~kg} \mathrm{~m}^{-3} \\
\text { P: } 6 \times 10^{-6} \mathrm{~kg} \mathrm{~m}^{-3}\end{array}$ \\
\hline$G_{\mathrm{MAX}} / G$ & $\begin{array}{l}\text { Ratio of the maximum fertilized plant growth } \\
\text { rate to the unfertilized rate (for use in the plant } \\
\text { sub-model) }\end{array}$ & 5 \\
\hline$G_{\mathrm{R}} / G_{\mathrm{A}}$ & Ratio of root to annual biomass growth & 1.0 \\
\hline$G_{\mathrm{R}} / G_{\mathrm{W}}$ & Ratio of root to woody biomass growth & 0.3 \\
\hline
\end{tabular}

parameter adjustment is needed to accommodate the structure chosen for the compartmental model. Roots are considered to populate only the mid-soil layer, while a large flux of nutrients due to litter decay goes directly into the top-soil layer. The enhanced exchange rate can be considered the result of root intrusion into the top-soil layer.

The surface water mass transfer rate has been correlated with depth and velocity (Kadlec and Hammer, 1982), and predicted values for $K_{\mathrm{W}}$ are available. The actual water velocity for solute transport is related to the computed superficial velocity trough a porosity factor $\Phi_{\mathrm{s}}$. The wetland clump structure results in one porosity for total water storage (permitting water to soak into hummocks), and a lower porosity for channelized flow. To more properly represent lateral solute transfer with water sheet movement, the porosity was reduced to $\Phi_{s}=0.5$. This value was supported by site data on channel velocities using dye tracers and by observed chloride 


\section{TABLE 3}

Initial conditions computation for the undisturbed wetland, Houghton Lake Treatment System-1978

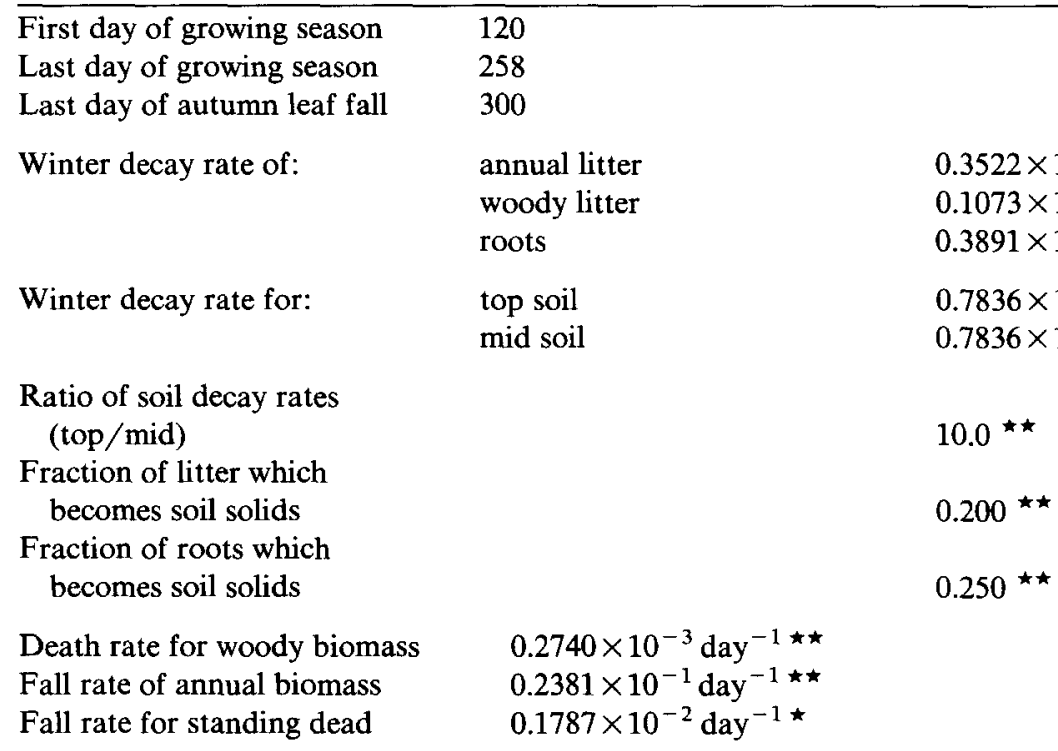

At above-ground live biomass peak

Annual biomass to roots ratio

\begin{tabular}{|c|c|}
\hline $0.9000 \star \star$ & \\
\hline $0.5000^{\star \star}$ & \\
\hline 0.8700 & $\mathrm{~kg}($ dry $) \mathrm{m}^{-2 \star \star}$ \\
\hline $0.1060 \times 10$ & $\mathrm{~kg}$ (dry) $\mathrm{m}^{-2 \star \star}$ \\
\hline 0.6000 & $\mathrm{~kg}($ dry $) \mathrm{m}^{-2 \star \star}$ \\
\hline 0.1500 & $\operatorname{kg}($ dry $) \mathrm{m}^{-2 \star \star}$ \\
\hline 0.9667 & $\mathrm{~kg}$ (dry) $\mathrm{m}^{-2 \star}$ \\
\hline $0.2300 \times 10^{-1}$ & $\operatorname{kg}($ dry $) m^{-2 \star \star}$ \\
\hline $0.5108 \times 10^{-1}$ & \\
\hline $0.2567 \times 10^{-2}$ & $\mathrm{~kg}$ \\
\hline $0.1087 \times 10^{-3}$ & \\
\hline $0.1087 \times 10^{-3}$ & $\mathrm{k}$ \\
\hline$\times 10^{-2}$ & $\mathrm{~kg} \mathrm{~m}^{-2} \mathrm{day}^{-1 \star(1)}$ \\
\hline
\end{tabular}

UNPERTURBED STATIONARY-STATE ANALYSIS

Availability of nitrogen during the growing season

Requirement for growth

$0.1520 \times 10^{-1} \mathrm{~kg} \mathrm{~m}^{-2}$

Input with rain

$0.1481 \times 10^{-3} \mathrm{~kg} \mathrm{~m}^{-2}$

Litter recovery, annual

$0.4122 \times 10^{-2} \mathrm{~kg} \mathrm{~m}^{-2}$

(27.11\%) 
TABLE 3 (continued)

\begin{tabular}{lll}
\hline Litter recovery, woody & $0.6441 \times 10^{-4} \mathrm{~kg} \mathrm{~m}^{-2}$ & $(0.42 \%)$ \\
Roots decay recovery & $0.2985 \times 10^{-2} \mathrm{~kg} \mathrm{~m}^{-2}$ & $(19.63 \%)$ \\
Soil release/decay & $0.5933 \times 10^{-2} \mathrm{~kg} \mathrm{~m}^{-2}$ & $(39.03 \%)$ \\
Surface water exchange & $0.0 \quad \mathrm{~kg} \mathrm{~m}^{-2}$ & $(0.0 \%)$ \\
Shortage (-)/excess (+) & $-0.1951 \times 10^{-2} \mathrm{~kg} \mathrm{~m}^{-2}$ & $(-12.83 \%)$ \\
Winter recovery inputs & $0.2283 \times 10^{-2} \mathrm{~kg} \mathrm{~m}^{-2}$ & $(15.01 \%)$ \\
Annual budget closure & $0.3312 \times 10^{-2} \mathrm{~kg} \mathrm{~m}^{-2}$ & $(2.18 \%)$ \\
Net precip. less evap. & $0.7370 \times 10^{-2} \mathrm{~m}$ &
\end{tabular}

Availability of phosphorus during the growing season

Requirement for growth

$0.1108 \times 10^{-2} \mathrm{~kg} \mathrm{~m}^{-2}$

Input with rain

Litter recovery, annual

Litter recovery, woody

Roots decay recovery

Soil release/decay

Surface water exchange

Shortage $(-)$ /excess $(+)$

Winter recovery inputs

Annual budget closure

$0.7404 \times 10^{-5} \mathrm{~kg} \mathrm{~m}^{-2}$

$0.4122 \times 10^{-3} \mathrm{~kg} \mathrm{~m}^{-2}$

$0.1804 \times 10^{-4} \mathrm{~kg} \mathrm{~m}^{-2}$

$0.3374 \times 10^{-3} \mathrm{~kg} \mathrm{~m}^{-2}$

$0.1855 \times 10^{-3} \mathrm{~kg} \mathrm{~m}^{-2}$

0.0

$-0.1470 \times 10^{-3} \mathrm{~kg} \mathrm{~m}^{-2}$

(0.67\%)

(37.22\%)

$(1.63 \%)$

$(30.46 \%)$

(16.75\%)

$(0.0 \%)$

$(-13.28 \%)$

$0.1631 \times 10^{-3} \mathrm{~kg} \mathrm{~m}^{-2}$

$0.1609 \times 10^{-4} \mathrm{~kg} \mathrm{~m}^{-2}$

$(1.45 \%)$

Parameters consistent with undisturbed, stationary-state case rates denoted by (1) are for yearday: 220 only.

* Computed.

$\star$ Data.

movement (Kadlec, 1979). It must be recognized that the clumps and hummocks, while out of the main stream of channel flow, do provide storage of water and therefore storage of solutes, much the same as the top-soil interstitial water. Interchange between the surface water sheet and this additional storage pool is complicated due to drainage and recharge as water levels fall and rise. Such wetland features are not yet sufficiently well understood to permit useful modeling. However, the exchange of solutes between surface water and clumps and hummocks can be approximated by adjustment of the mass transfer coefficient $K_{\mathrm{w}}$. The total mass transfer rate is enhanced by the presence of additional exchange routes, such as the utilization of nutrients by microorganisms followed by their death and sedimentation. Rapid decay of this detritus completes a time-delayed transfer from the surface water to topsoil water. Both enhanced mass transfer coefficients and sedimentation of rapidly decaying biomass were tested and found to adequately explain the observed phenomena. A factor of 10 on $K_{\mathrm{W}}$ allows reasonable predictions of interstitial water concentrations and localized plant growth due to wastewater addition. 


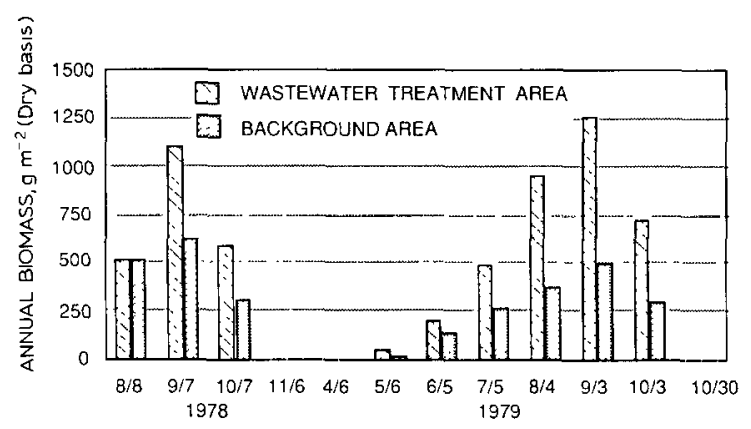

Fig. 4. Simulation results for annual live biomass increase at the Porter Ranch treatment facility (Houghton Lake, MI).

Having thus provided the necessary model parameters either from site data, from stationary-state rate calculations, from trial-and-error parameter fitting, or from heuristic assumptions, simulations of the Porter Ranch treatment facility were completed for the first 2 years of irrigation, 1978 and 1979. Not only was the distributed annual biomass pool properly described, but the predicted surface water concentrations were consistent with observations at the site.

Figures 4 and 5 depict one of the principal wetland responses to the nutrients found in wastewater. Based upon a simulation which begins with the startup of the Porter Ranch irrigation system (early in August 1978), the increase in annual biomass and annual litter due to fertilization is shown. The increase in the standing crop was well represented by the model, with Table 4 showing the predicted and observed productivity ratios. The plant sub-model produced the proper biomass for the growing seasons of 1978 and 1979. While the mismatch seen for June of 1979 is within the error bounds for the site data collected, it is also possible that an earlier starting

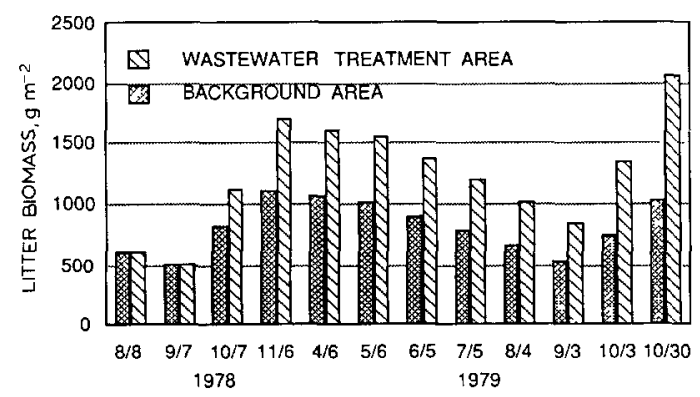

Fig. 5. Simulation results for the annual litter pool increase at the Porter Ranch treatment facility (Houghton Lake, MI). 


\section{TABLE 4}

The ratio of fertilized to background biomass productivity

\begin{tabular}{lll}
\hline Date & Prediction & Date \\
\hline August 1978 & 1.27 & 1.20 \\
September 1978 & 1.91 & 1.94 \\
June 1979 & 1.48 & 2.02 \\
September 1979 & 2.52 & 2.53 \\
\hline
\end{tabular}

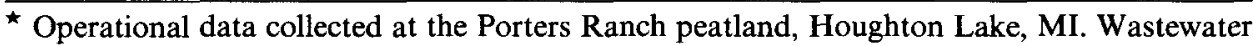
irrigation bagan 8 August 1978.

data for the growing season (before May 1) would improve the simulation results.

Figure 6 shows the spatial distribution of the annual biomass and annual litter compartments. The peak annual biomass for the unperturbed stationary state was estimated to be about $600 \mathrm{~g} \mathrm{~m}^{-2}$, likewise the peak annual litter pool was estimated to be $1060 \mathrm{~g} \mathrm{~m}^{-2}$. Slight variations around these values for the unaffected areas of the wetland, reflect natural fluctuations from year to year. The size of this zone of increased biomass was consistent with field data - both clip-plot measurements and aerial infrared imaging.

Removal of nutrients from surface waters by vascular plants is a multi-step process. However, a simple model of nutrient uptake was successful in describing the observed response to wastewater irrigation. This is important, because many proposed models for simulation of plants are complex. Such models may include fine detail parameters such as leaf resistance to $\mathrm{CO}_{2}$ diffusion, light intensity variations, leaf mortality rate, and stem mortality rate (Dixon, 1974). Dixon's model included 47 equations and over 80 parameters. It appears that simple biomass models will be adequate for engineering analyses of wetland treatment systems. Highly sophisticated

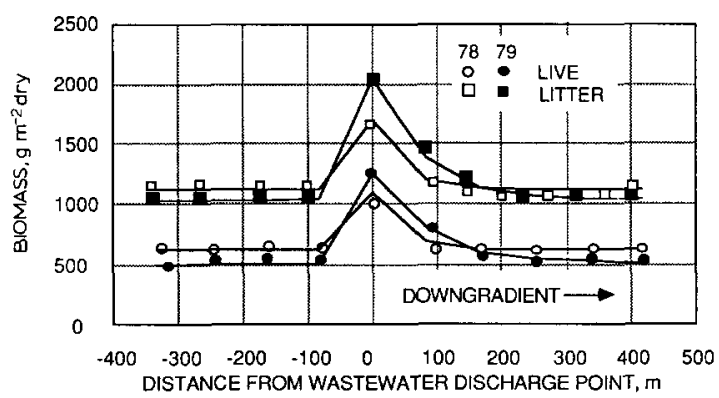

Fig. 6. Spatial variation of the peak annual live and peak annual litter biomass pools. Simulation of the Porter Ranch treatment facility (Houghton Lake, MI). 


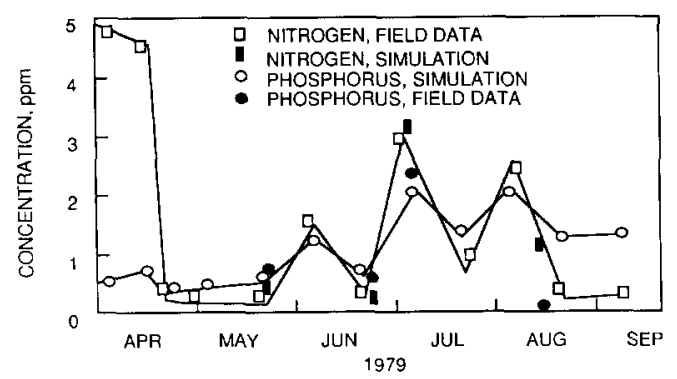

Fig. 7. Surface water concentrations of nitrogen and phosphorus near the discharge point. Porter Ranch treatment facility (Houghton Lake, MI), 1979.

models of plant growth are not warranted for simulation of overall wetland features.

Variations of nitrogen and phosphorus concentrations in surface water were predicted with similar success by this model. Figure 7 shows the change in concentration near the discharge point throughout the 1979 irrigations eason. There is good agreement between model predictions and field data, but values are strongly influenced by short-term events such as brief irrigation shut-downs and rain.

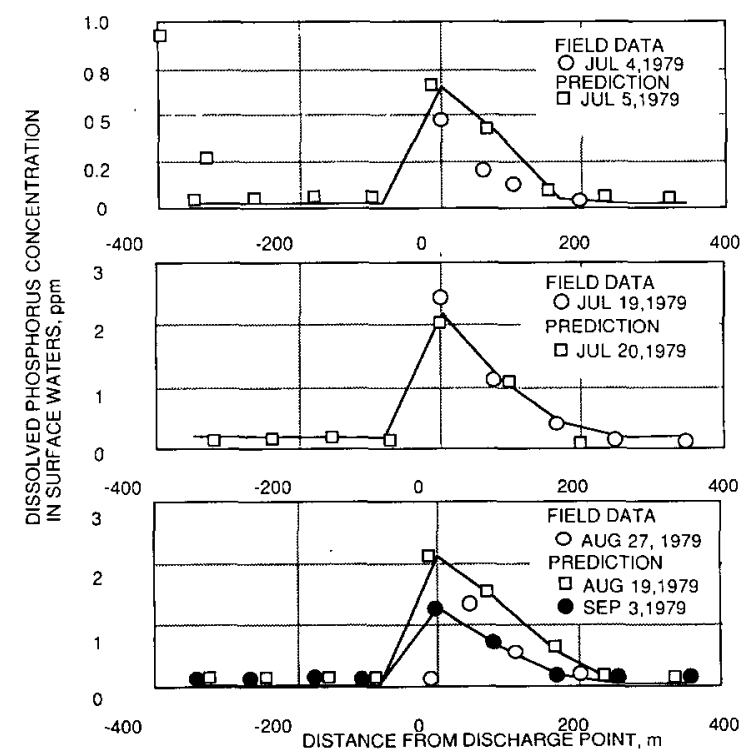

Fig. 8. Spatial distribution of dissolved phosphorus. Porter Ranch treatment facility (Houghton Lake, MI). 


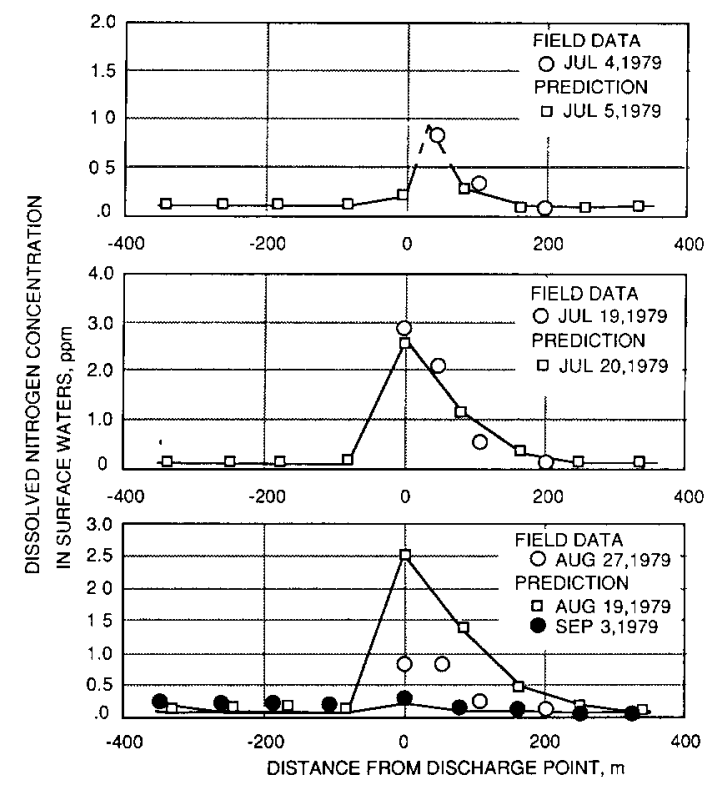

Fig. 9. Spatial distribution of dissolved nitrogen. Porter Ranch treatment facility (Houghton Lake, MI).

Simulation results showing the spatial distribution of phosphorus in surface water are compared to actual analyses of grab samples in Fig. 8. The corresponding information for nitrogen is presented in Fig. 9. Predicted movement of chloride was also consistent with available field data. The surface water sub-model which consists of a series of well-mixed cells was successful in producing the proper concentration fronts for dissolved nitrogen and phosphorus. The rapid changes in concentrations due to variations in the wastewater discharge rate or rain events can also be observed in these figures. The difference in 'wash-out' behavior between nitrogen and phosphorus is readily seen in the results for late August. Wastewater irrigation was stopped on 21 August.

\section{COROLLARY RESULTS FROM WETLAND SIMULATION}

Through the process of model verification, many of the phenomena at the Porter Ranch site became more easily understood. Certain hypotheses about ecosystem mechanisms (which were plausible, but not susceptible to practical or convenient test) have been supported or refuted by the comprehensive material balances performed. Similarly, the existence of other processes has been suggested, which were not considered before. A few examples follow. 


\section{Soil accretion}

Soil solids accumulate slowly in wetlands from decaying litter and from waterborne suspended solids. Accretion rates of imported sediments have been measured for salt marshes, but similar studies for fresh-water areas are not available (Boto and Patrick, 1978). Stewart and Reader (1972) cite rates in the range 0.03 to $0.06 \mathrm{~cm}$ year $^{-1}$ for peat accumulation for northern marshes, determined by carbon dating. This corresponds to approximately 300 to $600 \mathrm{~kg} \mathrm{ha}^{-1}$ year $^{-1}$ (dry weight). The soil accumulation rate at the Porter Ranch treatment site, prior to wastewater irrigation, was estimated using ${ }^{137} \mathrm{Cs}$ dating. It was found to be approximately $0.2 \mathrm{~cm}$ year ${ }^{-1}$ or 2000 $\mathrm{kg} \mathrm{ha}^{-1}$ year $^{-1}$ (Kadlec and Hammer, 1982). This is at the upper end of the range 0.1 to $0.2 \mathrm{~cm}$ year $^{-1}$, quoted by Farnham and Boelter (1976) for Minnesota peatlands. The accumulation rate of soil in wetland treatment systems due to the combined effects of sediments and biomass decomposition has not been measured.

Through simulation, two principal observations were made. First, annual litter and root decay control nutrient concentrations in interstitial water, and thus plant growth. In turn, plant growth determines the size of the litter pool available for subsequent years. As a result, the accumulation of soil solids may vary significantly from year to year in response to nutrient changes or hydrological factors (e.g. drought). The rate computed from measured annual biomass and litter pools may reflect only a short-term trend in soil accretion.

Secondly, ${ }^{137} \mathrm{Cs}$ tracer results may be more difficult to interpret than originally thought. Soil accumulation is inferred from the depth of a layer 'tagged' by radioactive cesium or lead. These deposits occurred in a known progression on several occasions - for cesium, principally in the late 1950's due to nuclear bomb testing in the atmosphere. The continued decay of soil solids in the wetland ecosystem releases nutrients for biomass production. This has the net effect of 'moving' nutrients and solids from the root-zone to the soil surface. Therefore over the course of several years, even if no net soil accretion occurs, the ${ }^{137} \mathrm{Cs}$ tagged layer will descend in the soil column. In periods of drought, soil decay rates can be greatly increased due to aerobic conditions in the upper soil horizons, further accelerating the downward movement of the radioactive tracer.

\section{Movement of concentration peaks}

At the Porter Ranch site, it has been observed that water samples taken at the irrigation point frequently have lower concentrations of nitrogen (as $\mathrm{NH}_{4}^{+}$) or phosphorus (as $\mathrm{PO}_{4}^{-3}$ ), than samples taken a short distance 
downgradient. Explanations of these downgradient peaks had been proposed over the years, but these were rather unsatisfying and generally untestable. The solution to this puzzle became apparent after some experience with simulation of water sheet concentrations.

The response of the model to irrigation shut-off is precisely the behavior described above. Without continued additions, the water mound on the upgradient side of the irrigation point begins to drain away. Water with background levels of nutrients soon flush the concentration peak downgradient. This can happen in less than $12 \mathrm{~h}$; thus overnight or weekend shutdowns (which are common practice) can readily produce the downgradient peak displacement observed.

\section{Mobility of solutes}

Nitrogen and phosphorus are removed rapidly from the surface waters and held within the stationary ecosystem, confined to the region surrounding the irrigation point. This region increases as the capacity of various consumption mechanisms become saturated. Chloride passes through the ecosystem with relative ease, moving with the velocity of surface water (making allowances for the effects of clumps and diffusional exchange with interstitial water). These features are properly produced by the model, and an important difference between nitrogen and phosphorus is highlighted. Phosphorus is held tightly by sorption mechanisms, while nitrogen is considerably more mobile. The movement of nitrogen in the following surface waters is limited by rapid uptake by plants. In the case of vascular plants, this immobilization depends upon transport vertically to the root-zone. If a particular wetland area is 'loaded' with nutrient from wastewater, and is subsequently flushed with waters at low background levels, the nitrogen will either be lost from the wetland or shifted downgradient. Phosphorus, however, will remain longer in an affected area. Since nitrogen immobilization depends upon plant uptake, early spring and late fall (when plants are dormant but water is still flowing) may see more massive displacement of nitrogen.

In design of wetland treatment facilities, hydrology will play a major role in nutrient removal from the wastewater. The consumption mechanisms have a greater capacity for nitrogen than for phosphorus. Nitrogen is largely removed from surface waters and incorporated into new plant tissues, but it should be noted that this has been made possible by a favorable hydrology. In order to permit uptake by vascular biomass, nitrogen must move vertically downward in the soil column to reach the root zone. Therefore it is apparent that deeper surface water and higher overland velocities would tend to transport nutrients, especially nitrogen, downgradient-spreading them over a larger area. 


\section{Wetland nutrient supply}

The majority of the nutrients available for plant growth in a natural wetland ecosystem are retained with a dynamic biomass pool. Inputs and outputs with rain or surface flows are small compared to the transfers which occur yearly between decaying biomass and growing plants.

It should be noted that the natural (pre-irrigation) biomass growth was marginally supported by the nutrient pool. Slight variations from year to year resulted in proportionate swings in annual productivity and biomass inventory. These perturbations can result from hydrological changes (e.g., drought induced acceleration of soil decomposition releasing nutrients; influx or loss of nutrients with boundary flows).

\section{Limiting nutrient}

The plant model used in these simulations takes the available nutrients in the soil interstitial water compartment and produces biomass of known composition. Nitrogen is the limiting nutrient which controls biomass production at the Porter Ranch site. This is true of areas both unaffected and affected by wastewater. Therefore, addition of phosphorus alone is unlikely to stimulate substantial increases in biomass in the wetland ecosystem.

Since the nutrient pool is supplied primarily by decaying plants, the inventories of phosphorus and nitrogen might be expected to remain at the proper ratio for plant growth. This would require, however, that the nutrients are equally immobilized. The strong adsorption of phosphorus on peat soils tends to insure a steady supply, while the nitrogen stockpile can be depleted by natural surface water flows. The release of nitrogen (as gaseous $\mathrm{N}_{2}$ ) by microbial activity can further insure that this component is always in greater demand.

\section{USES AND EXTENSIONS}

These spatially distributed hydrology and ecosystem models provide a convenient means by which the response of natural or constructed wetlands can be predicted, using sparse site information. This model, which accounts for movement of nutrients with surface water, allows the most fundamental engineering calculation - the material balance - to be applied to a wetland ecosystem. The mathematical models and the accompanying numerical solution techniques provide the prerequisites for work in three major areas:

(1) Management techniques for wastewater treatment systems can be investigated through simulation. 
(2) The importance of each design variable in natural and constructed wetland systems can be determined, and the performance of new designs predicted.

(3) Other models for compartmental processes can be tested within the context of a spatially distributed system.

This model is workable and accurate in predicting biomass, nutrient movement with surface waters, saturation phenomena, and other major site features. The set of parameters chosen, aside from being site specific for the Porter Ranch system, comprised but one combination which provides predictions consistent with observations. The interacting processes indigenous to wetlands, coupled with random natural events, make evaluation of individual model constants difficult. A program to make use of all available site data is a considerable undertaking; however, data are available which can provide greater insight into wetland processes when examined through the vehicle of simulation.

Obviously there are a great number of wetland phenomena which have not been considered in the present model and some of these may be important in improving future simulations. Improved simulations will go hand in hand with further field studies. The following items deserve attention:

(1) Ice - The freeze-up of surface waters in the wetland is accompanied by a number of interesting phenomena. For example, freezing water is known to exclude solutes from the ice lattice. These solutes are forced downward, potentially to the soil surface and even down into the soil column. This 'zone-refining' process may cause an important relocation of nutrients and other waterborne materials, thereby helping to prevent nutrient washout from the wetland (Kadlec, 1984).

Over-ice water flow is another wetland phenomena which is poorly understood. When ice forms, it traps the water sheet. If freezing continues down to the soil surface at some locations, overland flow under the ice is blocked. The water sheet is sloped downgradient and if a cleft is open in the ice, any unfrozen water will move up under the force of hydraulic gradient. The resulting over-ice flows could result in complex movements of solutes.

(2) Algae - Long acknowledged as a nutrient sink, algae are important in short-term material balances. Their short life cycle, however, tends to keep nutrients readily available; this has allowed successful modeling of gross nutrient dynamics without the need to consider algal contributions. Implicit in this conceptual model is an assumption that the algal biomass is stationary. This may not be the case. Algae represent a mobile, nutrient-rich, suspendable solid, available for transport downgradient (Kadlec, 1985). Such movements could potentially alter the overall nutrient distribution.

(3) Soil decomposition - Soil decay rates are not well-characterized for 
wetland simulation. Peatlands are known to subside after draining for agriculture, due to increased microbial activity in the aerobic soil. Effects of drought, for example, should be investigated.

(4) Microbial activity - Various bacteria utilize nitrogen and sulfur compounds. While studies have been completed on simple 'model' systems (Bartlett et al., 1979; Zoltek et al., 1979), Only limited rate data are available for use in an ecosystem model. The release of $\mathrm{N}_{2}$ or $\mathrm{H}_{2} \mathrm{~S}$ to the atmosphere may be an important factor in these elemental budgets.

(5) Suspended solids - While the transport of particulate wetland solids have received some attention in the literature (Jordan and Valiela, 1983; Kadlec, 1987), models have not been used in ecosystem simulation. Potentially important suspended solids include algal detritus and duckweed. Invertebrate populations represent a solids source both in the incoming wastewater and growing within the wetland. Movement of any of these suspended or suspendable solids can affect nutrient distribution across the wetland.

In conclusion, this mathematical model and the numerical solutions techniques described, provide not only a tool for engineering design of wetland treatment facilities, but also for future studies of wetland phenomena. The spatial model structure provides a framework for development of more sophisticated compartmental models, as well as a base with which simpler algorithms can be compared.

\section{REFERENCES}

Bartlett, M.S., Brown, L.C., Hanes, N.B. and Nickerson, N.H., 1979. Denitrification of in freshwater wetland soil. J. Environ. Qual., 3: 409-413.

Boto, K.G. and Patrick, W.H., Jr., 1978. The role of wetlands in the removal of suspended sediments. In: P.E. Greeson, J.R. Clark and J.E. Clark (Editors), Wetland Functions and Values: The State of our Understanding. American Water Resources Association, Minneapolis, MN, pp. 479-489.

Dixon, K.R., 1974. A model predicting the effects of sewage effluent on wetland ecosystems. Doctoral dissertation, University of Michigan, Ann Arbor, MI, $120 \mathrm{pp}$.

Farnham, R.S. and Boelter, D.H., 1976. Minnesota's peat resources: Their characteristics and use in sewage treatment, agriculture, and energy. In: D.L. Tilton, R.H. Kadlec and C.J. Richardson (Editors), Proc. Symp. Freshwater Wetlands and Sewage Effluent Disposal, May 1976, University of Michigan, Ann Arbor, MI, pp. 241-255.

Gupta, P.K., 1977. Dynamic optimization applied to systems with periodic disturbances. Ph.D. Thesis, University of Michigan, Ann Arbor, MI, 225 pp.

Hammer, D.E. and Kadlec, R.H., 1983. Design principles for wetland treatment systems. Rep. PB 83-188 722, U.S. Environmental Protection Agency, Ada, OK, 134 pp.

Hammer, D.E. and Kadlec, R.H., 1986. A model for wetland surface water dynamics. Water Resour. Res., 22: 1951-1958.

Jordan, T.E. and Valiela, I., 1983. Sedimentation and resuspension in a New England Salt Marsh. Hydrobiologia, 98: 179-184. 
Kadlec, R.H. (Editor), 1979. Wetland utilization for management of community wastewater, 1978 Operations Summary. Rep. to NSF-ASRA, PB 298 308, Houghton Lake, MI, 103 pp.

Kadlec, R.H., 1984. Freezing induced vertical solute movement in peat. In: 7 th Int. Peat Congr. Proc., Dublin, Vol. 4, pp. 248-262.

Kadlec, R.H., 1987. Sediment processes in wetlands. Water Res. (submitted).

Kadlec, R.H. and Hammer, D.E., 1980. Wetland utilization of management of community wastewater-1979 operations summary. Rep. to NSF-ASRA, PB-80 170 061, Houghton Lake, MI, 77 pp.

Kadlec, R.H. and Hammer, D.E., 1981. Nitrogen and phosphorus sorption in wetland water flow. In: Proc. 2nd World Congr. Chemical Engineering, Montreal, Que.

Kadlec, R.H. and Hammer, D.E., 1982. Pollutant transport in wetlands. Environm. Progr., 1: 206-211.

Kadlec, R.H. and Hammer, D.E., 1984. Wastewater renovation in wetlands: Six years at Houghton Lake. In: Proc. Water Reuse Symp. III, San Diego, CA, pp. 596-616.

Kadlec, R.H., Hammer, D.E., Nam, I.S. and Wilkes, J.O., 1981. The hydrology of overland flow in wetlands. Chem. Eng. Commun., 9: 331-334.

Mitsch, W.J., 1983. Ecological models for management of freshwater wetlands. In: S.E. Jørgensen and W.J. Mitsch (Editors), Application of Ecological Modeling in Environmental Management, Part B. Developments in Environmental Modelling, 4B. Elsevier, Amsterdam, pp. 283-310.

Mitsch, W.J., Taylor, J.R. and Madden, C., 1982. Models of North American freshwater wetlands. Int. J. Ecol. Environ. Sci., 51: 109-140.

Parker, P.E., 1974. A dynamic ecosystem simulator. Doctoral dissertation, University of Michigan, Ann Arbor, MI, 385 pp.

Patrick, W.H., Jr. and Reddy, K.R., 1976. Nitrification-denitrification reaction in flooded soils and water bottoms: Dependence on oxygen supply and ammonium diffusion. J. Environ. Qual., 5: 469-472.

Stewart, J.M. and Reader, R., 1972. Some considerations of production: Accumulation dynamic, in organic terrain. In: Proc. 4th Int. Peat Congr., Otaniemi, Finland, Vol. 1, pp. 247-358.

U.S. Environmental Protection Agency, 1984. The Ecological Impacts of Wastewater on Wetlands: An Annotated Bibliography. EPA-905/3-84-002, USEPA Region V, Chicago, IL, 1097 entries.

Zoltek, J., Bayley, S.E., Hermann, A.J., Tortora, L.R., Dolan, T.J., Graetz, D.A. and Erickson, N.L., 1979. Removal of nutrients from treated municipal wastewater by freshwater marshes. Final Rep. of the City of Clermont, Florida Center for Wetlands, University of Florida, Gainesville, FL, 325 pp. 